\title{
Improved estimation of nitrogen uptake in grasslands using the nitrogen dilution curve
}

\author{
Julian Reyes $^{1} \cdot$ Jürgen Schellberg $^{2} \cdot$ Stefan Siebert $^{2} \cdot$ Martin Elsaesser $^{3}$. \\ Jennifer Adam ${ }^{1}$ - Frank Ewert ${ }^{2}$
}

Accepted: 1 June 2015 /Published online: 18 June 2015

(C) INRA and Springer-Verlag France 2015

\begin{abstract}
The nitrogen (N) dilution curve is a useful tool for farmers to assess the effectiveness of fertilizer application. The $\mathrm{N}$ dilution curve describes the decrease in plant $\mathrm{N}$ as biomass increases. This concept has not yet been tested for its applicability and robustness under different cutting regimes in grasslands. We conducted a principal components analysis on biomass yield and $\mathrm{N}$ concentration data to discern relationships among experimental, climatic, and management factors. Next, two $\mathrm{N}$ dilution curve parameters were calibrated for different cutting frequencies. We compared $\mathrm{N}$ uptake using four different methods utilizing calibrated $\mathrm{N}$ dilution curves, a reference curve, and different cutting regimes representing different physiological ages of the crops at cutting. Our results show that excluding cutting frequency information overestimates values of $\mathrm{N}$ uptake. Calibration of the $\mathrm{N}$ dilution curve according to cutting frequency improves $\mathrm{N}$ uptake estimates relative to observed values. Therefore, $\mathrm{N}$ uptake is better estimated using both the $\mathrm{N}$ dilution curve and the cutting regime information.
\end{abstract}

Keywords Nitrogen dilution curve · Critical nitrogen uptake · Critical nitrogen concentration · Grassland management . Cutting $\cdot$ Empirical modeling

Julian Reyes

julian.reyes@email.wsu.edu

1 Department of Civil and Environmental Engineering, Washington State University, PO Box 642910, Pullman, WA 99164-2910, USA

2 Institute of Crop Science and Resource Conservation, University of Bonn, Katzenburgweg 5, D-53115 Bonn, Germany

3 Agricultural Center for Cattle Farming, Grassland Management, Dairy Processing, Wildlife and Fishery for Baden-Wuerttemberg, Stuttgart, Germany

\section{Introduction}

During the past 50 years, grasslands have been increasingly managed to support growing agricultural demands (Gibon 2005; Kemp and Michalk 2007). The application of nitrogen (N) to grassland is one of the major management tools farmers have to influence yield and quality. Different management strategies can be important in reducing negative impacts to our environment like $\mathrm{N}$ leaching into subsurface and aquatic systems (Galloway et al. 2003; Matson et al. 1997). While much research has focused on effective levels of nitrogenous fertilizer application, there are knowledge gaps in how cutting frequency (i.e., defoliation) affects $\mathrm{N}$ balances in grasslands (Gruber et al. 1999; Herrmann et al. 2005; Wilman and Wright 1986).

The $\mathrm{N}$ dilution curve can serve as a robust estimation of the $\mathrm{N}$ status of crops, including grasses, providing farmers and land managers an effective management tool (Farruggia et al. 2004; Lemaire et al. 2008). The $\mathrm{N}$ dilution curve depicts changes in plant $\mathrm{N}$ concentration during growth. The critical $\mathrm{N}$ dilution curve represents the upper limit of plant $\mathrm{N}$ concentration with which maximum biomass yield can be achieved during growth. Both critical and general $\mathrm{N}$ dilution curves have been empirically determined for many crops (Flénet et al. 2006; Gislum and Boelt 2009; Herrmann and Taube 2004; Lemaire et al. 2008; Marino et al. 2004). Values below the critical $\mathrm{N}$ dilution curve represent sub-optimal nutrient conditions and values above represent supra-optimal conditions (Gastal and Lemaire 2002).

Previous work on $\mathrm{N}$ fertilizer effects on biomass and annual $\mathrm{N}$ extraction from soil has shown that more total $\mathrm{N}$ is harvested with biomass at high cutting frequencies than at lower ones (Burton et al. 1963; Fairey 1991; Madakadze et al. 1999; Zhang et al. 1995). Long-term, frequent cutting leads to a high density of leaf tillers rich in $\mathrm{N}$, whereas low cutting frequency 
favors grass species that produce more stems at lower density for the same amount of biomass per unit ground area (Dahl and Hyder 1977). Existing knowledge on how cutting frequencies affect the $\mathrm{N}$ dilution curve is absent. Some evidence of an intrinsic effect of cutting frequency in grassland on the $\mathrm{N}$ dilution curve at late cutting stages can be implicitly supported through ecophysiological observations. Suppression and shading of lower leaves, as well as the apical dominance of the main tiller before late cutting, lead to a reduced number of leaf primordia and emerging side tillers near the ground (Dahl and Hyder 1977). Thus, the remaining photosynthetically active leaf area rich in $\mathrm{N}$ is low.

The $\mathrm{N}$ dilution curve is the result of two ecophysiological processes that occur as biomass increases: (1) self-shading of leaves and (2) a decrease in leaf to stem ratio (Gastal and Lemaire 2002; Lemaire and Gastal 1997). The first process results in less $\mathrm{N}$ in shaded leaves due to a decline in photosynthetic capacity in the total metabolic component of the plant, where photosynthesis occurs (Lemaire et al. 2008). The second process represents an increase in the structural component (i.e., tissues) mainly in the stems of the plant which contain less N than leaves (Greenwood et al. 1990; Justes et al. 1994; Lemaire and Gastal 1997; Lemaire et al. 2008).

Although advances in Earth systems modeling have begun incorporating more grassland management processes, their representation in process-based models which consider carbon $(C), N$, and water cycling for grassland management is still in its infancy and proper evaluation of the interactions among different ecosystem processes remains a challenge (Bestelmeyer and Briske 2012; Bondeau et al. 2007; Hidy et al. 2012). Even so, most models dealing with coupled C$\mathrm{N}$ cycles and climate have a simplistic representation of $\mathrm{N}$ uptake (Zaehle and Dalmonech 2011). Improved N uptake estimates can play a role in future modeling efforts and better simulate management impacts on the environment and potential $\mathrm{C}$ sequestration in a changing climate (Ammann et al. 2009; Galloway et al. 2003; Parton et al. 1995).

We present a first look at how cutting frequency as a major management factor on permanent grassland affects biomass yield, $\mathrm{N}$ concentration, and potential $\mathrm{N}$ uptake using the $\mathrm{N}$ dilution curve concept, which can be used to calculate potential plant $\mathrm{N}$ uptake. Since the $\mathrm{N}$ dilution curve has been used to investigate fertilizer effects on potential $\mathrm{N}$ uptake, we hypothesize that cutting system and frequency can also be incorporated into the $\mathrm{N}$ dilution curve.

The objectives of this paper were to (1) determine the relative importance of cutting frequency compared to other management factors and site characteristics, (2) develop $\mathrm{N}$ dilution curve parameters specific to cutting systems, and (3) assess shifts in the $\mathrm{N}$ dilution curve due to cutting systems in calculating $\mathrm{N}$ uptake. To date, most research has involved parameterization of the $\mathrm{N}$ dilution curve related to individual plant species, and have not looked at applications of the $\mathrm{N}$ dilution curve related to management effects on grassland, such as cutting. This paper provides an indication of the spread of uncertainty related to critical $\mathrm{N}$ uptake, which can better our understanding of $\mathrm{N}$ cycling in grasslands, as well as how to better simulate these processes in models.

\section{Materials and methods}

\subsection{Overview of analysis}

Data from a variety of cutting and fertilizer experiments were obtained from sites throughout Germany for this study. We performed a principal components analysis (PCA) to help to explain relationships between biomass yield, $\mathrm{N}$ concentration, climate, and management, such as cutting system. $\mathrm{N}$ dilution curve parameters for different cutting systems were determined using relationships developed between $\mathrm{N}$ concentration and yield. We report the performance of calibrated $\mathrm{N}$ dilution curves for each cutting system using the coefficient of determination $\left(R^{2}\right)$ and root mean squared error (RMSE). Finally, $\mathrm{N}$ uptake was computed using a variety of methods, employing the $\mathrm{N}$ dilution curve concept.

\subsection{Data}

Data were obtained from grassland experiments which included both biomass yield and $\mathrm{N}$ concentration at specific cutting intervals (Elsäßer 1999; Pavlů et al. 2011). Figure 1 depicts an example experimental design for different $\mathrm{N}$ fertilizer experiments in permanent grassland. The compiled dataset represented a diverse mix of experimental factors, such as cutting frequency and fertilizer type (Table 1). Biomass yield and $\mathrm{N}$ concentration observations were partitioned to reflect the appropriate cutting frequency for the PCA, N dilution curve model development, and evaluation (see Section 2.5).

\subsection{Principal components analysis}

Principal components analysis (PCA) is a statistical method to transform a set of potentially correlated data points into linearly uncorrelated variables called principal components. We used the R programming platform (version 2.14.2) for this analysis. The goals of the PCA were to (1) determine the relationships between management factors, climatic and site characteristics, biomass yield, and $\mathrm{N}$ concentrations, and (2) reduce the number of variables within the dataset to better understand relationships among them (Dunteman 1989). The PCA works best with linearly related data, but monotonically 
Fig. 1 Aerial photograph of the permanent grassland with an $\mathrm{N}$ fertilizer experiment at the "Klein-Altendorf" research station at the University of Bonn in western Germany

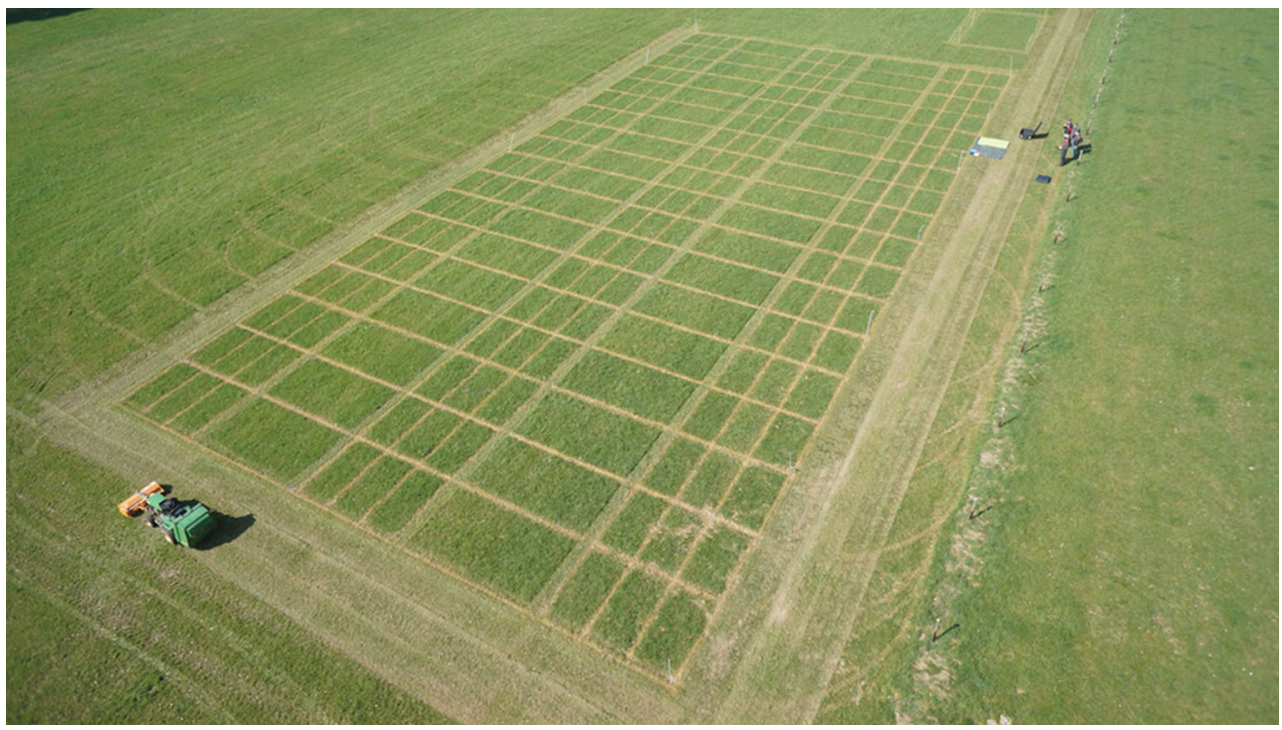

related data are also sufficient. Linearization was not performed to avoid potential loss of information in the data.

The following explanatory variables were chosen for the PCA: biomass yield, $\mathrm{N}$ concentration, cutting frequency (i.e., cutting system), cut number, fertilizer application, precipitation, temperature, elevation, year, site, replicate, and liming. These variables are present in the aforementioned dataset (Table 1). Fertilizer application and liming were categorical variables having only two possibilities: yes or no.

A dimension reduction exercise was conducted to optimize the cumulative proportion of variance explained by two principal components and the number of explanatory variables. Variables within the diverse dataset may be redundant, correlated to others, and/or not representative of each experimental design as described in Section 2.2.

\subsection{Description of the $\mathrm{N}$ dilution curve}

The $\mathrm{N}$ dilution curve is represented by a negative power function:

$\mathrm{N} \%=a W^{-b}$

where $\mathrm{N} \%$ represents the $\mathrm{N}$ concentration in biomass expressed as a percentage of weight and $W$ is biomass in $\mathrm{t} \mathrm{ha}{ }^{-1}$. The coefficient "a" represents the $\mathrm{N}$ concentration when $W$ is $1 \mathrm{t} \mathrm{ha}^{-1}$. The coefficient " $\mathrm{b}$ " is dimensionless and represents the plant's response to declining light in a dense canopy (Lemaire and Gastal 1997).

\subsection{Development and evaluation of the $\mathrm{N}$ dilution curves}

We developed $\mathrm{N}$ dilution curves following wellestablished statistical methods described by Justes et al. (1994) and Lemaire and Gastal (1997). We plotted biomass yield (dependent variable, $\mathrm{kg}$ per ha per cut) against $\mathrm{N}$ fertilizer levels (independent variable, $\mathrm{kg}$ per ha per year) and determined the maximum value from this relationship, which followed the law of diminishing returns. From these plots, we identified the critical points at which no further increase in biomass yield would occur with additional fertilizer application. Specific datasets used to identify these critical points are labeled in Table 1. We found the critical points for each cutting regime, and then developed the $\mathrm{N}$ dilution curves for 2-, 3-, and 4-cut systems by running a nonlinear regression through them. Generalized parameters for temperate grasslands proposed by Lemaire and Gastal (1997) were used as initial values $(a=4.8, b=$ 0.32 ). The generated $\mathrm{N}$ dilution curve is referred to as the "Lemaire reference curve" henceforth.

The goodness of fit of the calibrated $\mathrm{N}$ dilution curves with respect to the critical points was measured using $R^{2}$ and RMSE. Analyses for goodness of fit were performed to compare model regressions on (1) all critical points regardless of cutting system, and (2) only critical points within a particular cutting system.

\subsection{N uptake calculation methodologies}

Four computational methods were used to compute $\mathrm{N}$ uptake, and results were compared with observed values. The first two methods included annual biomass yield with no consideration of cuts, while the other two used biomass yield at each cut.

Lemaire-annual biomass method The Lemaire reference curve was used with total seasonal biomass yield values to determine the critical $\mathrm{N}$ concentration $(\mathrm{CNC})$ and compute $\mathrm{N}$ uptake. Cutting frequency was not taken into consideration. 


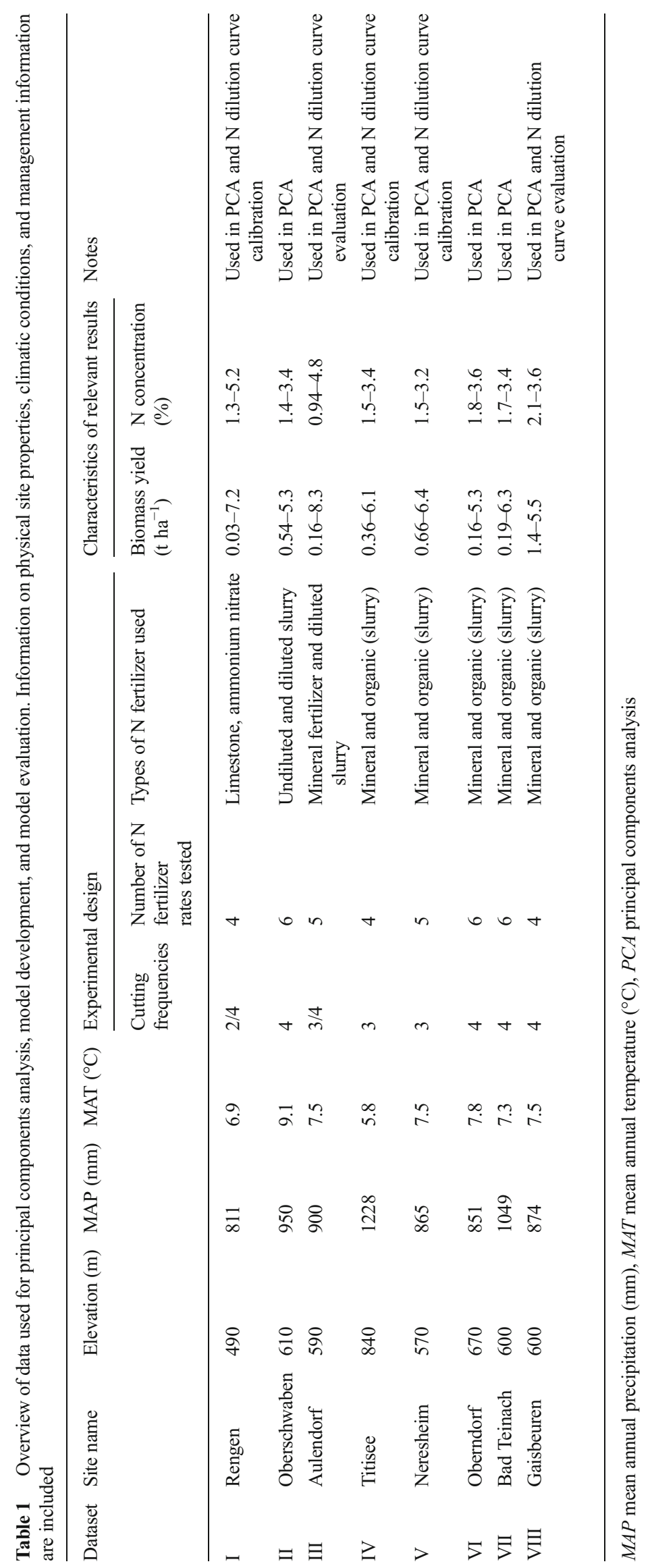


We applied the following equation, which is analogous to the $\mathrm{N}$ dilution curve presented in Section 2.4:

$N_{\mathrm{c}}=a \times\left[\mathrm{BM}_{\mathrm{a}} / 1000\right]^{-b}$

where $N_{\mathrm{c}}$ is the $\mathrm{CNC}(\%), \mathrm{BM}_{\mathrm{a}}\left(\mathrm{kg} \mathrm{ha}^{-1}\right)$ is the observed annual biomass yield. The parameters $a$ and $b$ are constants of values 4.8 and 0.32 , respectively, which were general $\mathrm{N}$ dilution curve parameters described by Lemaire and Gastal (1997). $\mathrm{N}$ uptake is determined as follows:

$N_{\text {uptake }}=\left(N_{\mathrm{c}} / 100\right) \times\left(\mathrm{BM}_{\mathrm{a}}\right)$

where $N_{\text {uptake }}$ is the annual critical N uptake ( $\mathrm{t} \mathrm{ha}^{-1}$ ) and represents the optimal amount of $\mathrm{N}$ uptake, with neither surplus nor deficiency.

Constant $\mathbf{N}$ method A constant $N_{\mathrm{c}}$ value of $2.5 \%$ was used with total seasonal biomass yield values to compute $\mathrm{N}$ uptake as in Eq. 3. This value represents an average $\mathrm{N}$ concentration across multiple published datasets (Whitehead 1995) and also the average $\mathrm{N}$ concentration measured for 3-cut and 4-cut systems (Table 1).

Lemaire-cutting method The Lemaire reference curve was used with observed biomass yield values at each individual cut to find the CNC. Using data of biomass yield at each cut, $\mathrm{CNC}$ was calculated as follows:

$N_{\mathrm{c}, \operatorname{cut}(\mathrm{i})}=a \times\left[\left(\mathrm{BM}_{\mathrm{c}(\mathrm{i})}\right) / 1000\right]^{-b}$

where $N_{\mathrm{c} \text {, cut(i) }}$ is the $\mathrm{CNC}$ of the crop at the $i^{\text {th }}$ cut and $\mathrm{BM}_{\mathrm{c}(\mathrm{i})}$ is the observed biomass yield at the $i^{\text {th }}$ cut. The critical $\mathrm{N}$ uptake at the $i^{\text {th }}$ cut is determined (Eq. 5) and then summed over the total number of cuts (i) to determine total annual $\mathrm{N}$ uptake (Eq. 6).

$N_{\text {uptake, cut(i) }}=\left(N_{\mathrm{c}, \operatorname{cut}(\mathrm{i})} / 100\right) \times\left(\mathrm{BM}_{\mathrm{c}(\mathrm{i})}\right)$

$N_{\text {uptake-total }}=\sum_{i=1}^{n} N_{\text {uotake, } \operatorname{cut}(i)}$

Calibrated Lemaire-cutting method Critical $\mathrm{N}$ uptake was computed and summed over all cuts similar to Eqs. 4-6 in the Lemaire-cutting method. However, different coefficient values $(a, b)$ were obtained for each cutting system (presented in Section 3.2).

\section{Results and discussion}

\subsection{Importance of factors affecting the $\mathbf{N}$ dilution curve}

Using all explanatory variables, the first two principal components were able to explain half of the variance within our dataset.
We increased the cumulative proportion of variance explained by the two principal components to $60 \%$ through dimension reduction by eliminating the liming, replicate, and site variables. We ended dimension reduction at this point to retain variables related to environmental conditions and management factors.

Explanatory variables related to management (cutting system, cut number, and fertilizer application) affect the first principal component axis, whereas those related to site characteristics (temperature and year) affect the second axis (Fig. 2). We expected the biomass and $\mathrm{N}$ concentration vectors to point opposite each other $\left(180^{\circ}\right)$ because of the negative correlation between the two variables in the $\mathrm{N}$ dilution curve. The obtuse angle between them suggests that other factors influence the $\mathrm{N}$ dilution curve relationship, such as environmental conditions and/or management activities (Leps and Smilauer 2003). The arrow length of cutting system indicates that this variable can best explain the variation in principal components axis one. Additionally, cutting system plays a larger role than the other management factors, like fertilizer level, in determining the $\mathrm{N}$ dilution curve.

\section{2 $\mathrm{N}$ dilution curve for different cutting regimes}

We produced $\mathrm{N}$ dilution curves for different cutting systems (Fig. 3). The Lemaire reference curve served as a

\section{Principal Component 2}



Fig. 2 Ordination diagram produced from a principal components analysis showing how climate, site, and management factors interact and affect the primary variables of interest, biomass yield, and $\mathrm{N}$ concentration. Each principal components axis measures the amount of variation by the original variable with respect to that particular principal component. The obtuse angle that exists between the biomass yield and $\mathrm{N}$ concentration vector suggests other factors influence the relationship between these two variables, which determine the $\mathrm{N}$ dilution curve 



Fig. 3 a Critical $\mathrm{N}$ dilution curves based on calibrated parameters for different cutting systems with the Lemaire reference curve. b Evaluation of the three-cut $\mathrm{N}$ dilution curve with data of similar cutting system at two fertilizer levels. Most values from higher levels of fertilizer application appear above the $\mathrm{N}$ dilution curve indicating supra-optimal, or more than necessary amount of $\mathrm{N}$ to achieve maximum yield. $\mathbf{c}$ Evaluation of the four-cut $\mathrm{N}$ dilution curve with data of similar cutting systems at two fertilizer levels. Values for both levels of fertilizer application do not form a consistent pattern, indicating bias in model development data or inadequate representation of different $\mathrm{N}$ fertilization levels

baseline to test its general performance against the data, as well as a starting point to develop calibrated $\mathrm{N}$ dilution curves using data collected from different cutting systems.

The coefficients $(a, b)$ of the $\mathrm{N}$ dilution curve are reported for different cutting regimes: 2-cut system (3.52, 0.38), 3-cut system $(2.75,0.23)$, and 4-cut system $(4.19,0.33)$. The fit of the curves through each cutting system's data points yields the following $R^{2}$ and RMSE values: 2-cut system $(0.83,0.21), 3$ cut system $(0.52,0.33)$, and 4-cut system $(0.57,0.40)$. Additionally, the $R^{2}$ and RMSE values are reported for fitting the Lemaire reference curve through all points $(0.45,0.50)$. Higher $R^{2}$ and lower RMSE values indicate a better fit of the $\mathrm{N}$ dilution curves regressing through specific cutting regimes' critical points compared with regression through the Lemaire reference curve through all points.

The $\mathrm{N}$ dilution curve in Fig. 3 for the 4-cut system lies closest to the Lemaire reference curve. It was expected that the $\mathrm{N}$ dilution curve of the 3-cut system would lie between the 2-cut and 4-cut curves. However, their placement was likely due either to the bias in the 3-cut data toward lower $\mathrm{N}$ concentration values at higher biomass yields or a lack of sufficient critical points at lower biomass yields. These $\mathrm{N}$ dilution curves fit well with the expectations that higher cutting systems provide higher $\mathrm{N}$ concentration values throughout the season, due to cutting of younger biomass.

Shifts in the $\mathrm{N}$ dilution curves related to cutting systems suggest that different $\mathrm{N}$ concentrations and $\mathrm{N}$ yields can be obtained at different growth intervals depending on the amount and physiological age of the biomass. Similar conclusions were found looking at $\mathrm{N}$ dilution curve parameters for perennial ryegrass (Gislum and Boelt 2009). Frequent defoliation decreases the internal partitioning of $\mathrm{N}$ from older leaves to newer ones forming. Therefore, additional defoliation events earlier in the growing season will shift the $\mathrm{N}$ dilution curve higher due to higher $\mathrm{N}$ concentrations at lower biomass intervals. Our analysis similarly suggests that $\mathrm{N}$ concentration increases across a range of biomass yields with more cutting frequency with or without additional fertilizer application (Herrmann et al. 2005; Nevens and Rehuel 2003).

\subsection{Evaluation of the $\mathbf{N}$ dilution curves}

For evaluation, data not used for $\mathrm{N}$ dilution curve development were plotted with the calibrated 3-cut and 4-cut $\mathrm{N}$ dilution curves (Fig. 3). The 3-cut $\mathrm{N}$ dilution curve compared with observed values suggests that the lower fertilizer level $\left(115 \mathrm{~kg} \mathrm{~N} \mathrm{ha}^{-1}\right.$ year $\left.^{-1}\right)$ may be sub-optimal for this grassland. Three different sites' data were used to develop the 3-cut N dilution curve. Fertilizer application levels and climate characteristics for the evaluation site were within the range of the calibration/development sites. 
Data for the 4-cut $\mathrm{N}$ dilution curve evaluation formed no consistent pattern according to fertilizer application level. Additionally, the majority of points lay beneath the 4-cut $\mathrm{N}$ dilution curve, indicating sub-optimal nutrient conditions, even for fertilizer application rates greater than $200 \mathrm{~kg} \mathrm{~N}$ $\mathrm{ha}^{-1}$ year $^{-1}$. The scatter of data points could be due to different types of fertilizer used (i.e., synthetic fertilizer vs. organic slurry), which is not considered here. While the 3-cut calibrated $\mathrm{N}$ dilution curve fits other experimental data well, the 4-cut calibrated $\mathrm{N}$ dilution curve does not.

\subsection{Critical $\mathrm{N}$ uptake calculation methodologies}

\subsubsection{Critical $N$ uptake methods and observed values}

Large differences exist among the critical $\mathrm{N}$ uptake values calculated using the methods presented in Section 2.6 and observed $\mathrm{N}$ uptake values (Fig. 4). It is important to note that observed $\mathrm{N}$ uptake values were not necessarily critical values. A majority of observed values in the 3-cut system lies below calculated critical $\mathrm{N}$ uptake values. However, critical $\mathrm{N}$ uptake values from the Lemaire-annual biomass method act as a lower boundary to observed values for the 4-cut system. Additionally, more calculated critical $\mathrm{N}$ uptake values match observed values in the 4-cut system than in the 3-cut system.

In both the 3- and 4-cut systems, critical $\mathrm{N}$ uptake values calculated from the Lemaire-cutting method form an upper boundary to observed values, indicating potential $\mathrm{N}$ limitation in the datasets or an overestimation of calculated $\mathrm{N}$ uptake. Since most observed data have had fertilizer treatment applied (i.e., reducing or removing $\mathrm{N}$ limitation), it is likely that the
Lemaire-cutting method overestimates critical $\mathrm{N}$ uptake. Agnusdei et al. (2010) also found the Lemaire reference curve to provide much higher $\mathrm{N}$ uptake values than critical $\mathrm{N}$ uptake derived from experimental data. By incorporating calibrated $\mathrm{N}$ dilution curves along with biomass yield and $\mathrm{N}$ concentration information at each cut, these methods move toward more realistic critical $\mathrm{N}$ uptake values.

The large spread among calculated critical $\mathrm{N}$ uptake values of any method and observed values suggest yield gaps related to resource limitations of water or nutrients. Additionally, observed $\mathrm{N}$ uptake values could be simply under supra-optimal conditions and not representative of different nutrient conditions as assumed earlier. Moreover, some calculated methods may overestimate $\mathrm{N}$ uptake values due to the site-specific nontransferable nature of the data used to produce the $\mathrm{N}$ dilution curve.

\subsubsection{Constant $N$ method}

Using a well-established average $\mathrm{N}$ concentration value across multiple cutting systems demonstrates how data availability affects $\mathrm{N}$ uptake calculations. A constant $\mathrm{N}$ concentration of $2.5 \%$ was assumed for both the 3 - and 4-cut systems. For the 3 -cut system, the majority of observed values lie below those calculated from the constant $\mathrm{N}$ method. The constant $\mathrm{N}$ method provides a nice fit for observed $\mathrm{N}$ uptake values in the 4-cut system.

In cases where data on $\mathrm{N}$ concentration might be sparse or unavailable, a prescribed constant value can be used to obtain a good fit with observed $\mathrm{N}$ uptake values at certain biomass yields. The constant $\mathrm{N}$ method shows a fair approximation to
Fig. 4 Comparison of critical N uptake values calculated from $\mathrm{N}$ dilution curve-derived methods with observed values. Different colors and shapes represent aforementioned techniques to calculate $\mathrm{N}$ uptake. In both cutting systems, the Lemairecutting method overestimates annual $\mathrm{N}$ uptake. Using biomass yield and $\mathrm{N}$ concentration from each cut (i.e., calibrated Lemairecutting method) produces values closer to observed, indicating the importance of cutting system information in $\mathrm{N}$ dilution curve and $\mathrm{N}$ uptake studies.

Nonetheless, using a constant $\mathrm{N}$ concentration or yearly values is preferable to the Lemaire-cutting method for calculating annual $\mathrm{N}$ uptake

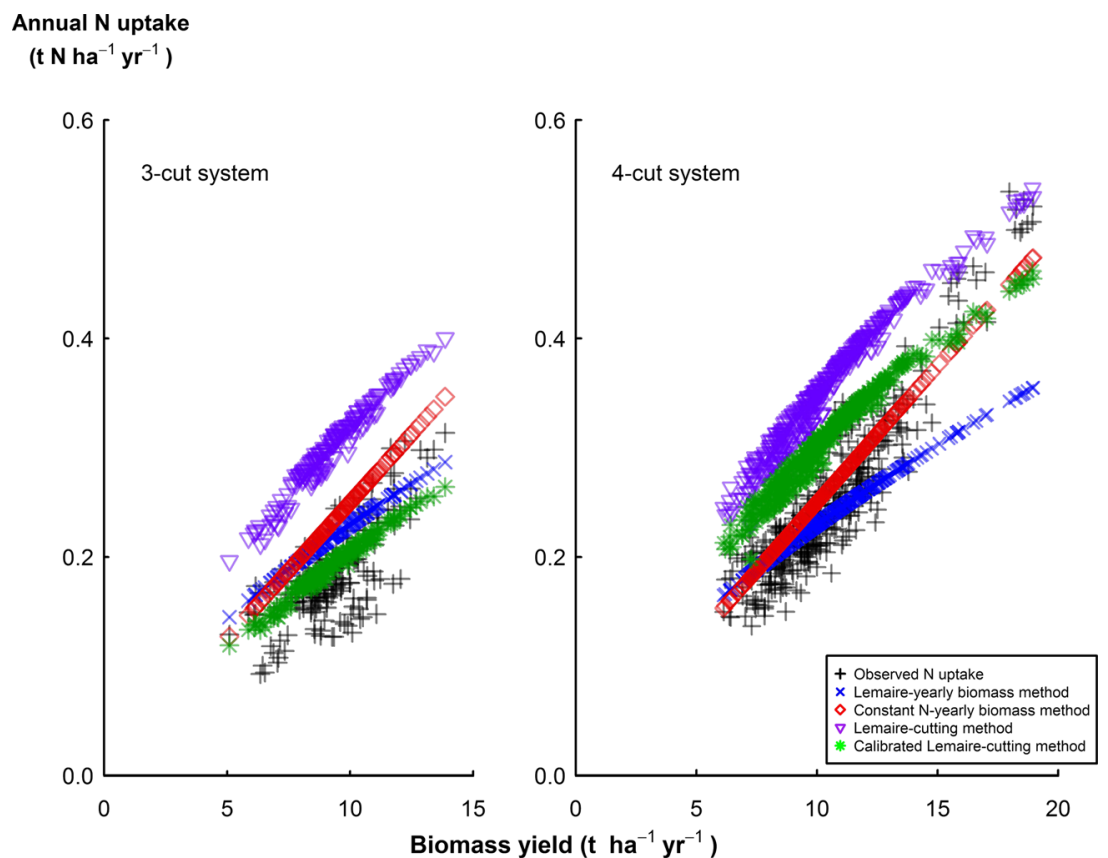


observed $\mathrm{N}$ uptake values, but does not represent physical processes within the plant that occur as biomass values increase. Similar to N concentration reaching a steady-state value as biomass yield increases, we expect a leveling off in $\mathrm{N}$ uptake with increasing biomass. Potential overestimation of critical $\mathrm{N}$ uptake occurs at higher biomass yield values due to the absence of any biophysical representation in the constant $\mathrm{N}$ method, such as the law of diminishing returns related to fertilizer application and biomass. The lack of ecophysiological limitation due to water stress or nutrient availability constrains the general applicability of this method.

\subsubsection{Calibrated Lemaire-cutting method}

Differences between critical N uptake values from the calibrated Lemaire-cutting method provide the most realistic picture of $\mathrm{N}$ uptake showing a mix of both supra- and sub-optimal conditions of $\mathrm{N}$. If the Lemaire-cutting method was used for critical $\mathrm{N}$ uptake, observed values would always indicate sub-optimal nutrient conditions. Essentially, the optimal amount of $\mathrm{N}$ uptake would be overestimated compared to what $\mathrm{N}$ uptake actually occurs. The calibrated Lemaire-cutting method does not overestimate critical $\mathrm{N}$ uptake as much in both cutting systems because most critical $\mathrm{N}$ uptake values are within the range of observed N uptake values. Since we chose experimental data with a variety of fertilizer application levels, we should expect a mix of critical $\mathrm{N}$ uptake below and above the curve.

\subsubsection{Comparison between annual and per cut values}

Critical $\mathrm{N}$ uptake values from the Lemaire-annual biomass method and Lemaire-cutting method were quite large. These methods used annual biomass yield values and biomass yield at each cut, respectively. As an illustration, one may take an annual biomass value of $12,000 \mathrm{~kg} \mathrm{ha}^{-1}$ and assume equal partitioning among cuts. This will result in a difference of about $100 \mathrm{~kg} \mathrm{ha}^{-1}$ in critical $\mathrm{N}$ uptake for a 3-cut system and $140 \mathrm{~kg} \mathrm{ha}^{-1}$ for a 4-cut system (Fig. 4). Differences in critical $\mathrm{N}$ uptake increased slightly as annual biomass yield increases for both cutting systems (Fig. 4).

\subsubsection{Comparison between Lemaire-cutting and calibrated Lemaire-cutting methods}

Differences in critical $\mathrm{N}$ uptake values were also distinct between the Lemaire-cutting method and calibrated Lemairecutting method, the latter taking into account specific cutting system parameters. As an example, an annual biomass of $12 \mathrm{tha}^{-1}$ year $^{-1}$ and an equal partitioning of yield among cuts would result in a critical $\mathrm{N}$ uptake difference of at least $100 \mathrm{~kg} \mathrm{~N} \mathrm{ha}^{-1}$ year $^{-1}$ (3-cut system) and of at least $50 \mathrm{~kg} \mathrm{~N} \mathrm{ha}^{-1}$ year $^{-1}$ (Fig. 4; 4-cut system).
Differences between the Lemaire-cutting method and the calibrated Lemaire-cutting method for the 3-cut system are larger than those for the 4-cut system, suggesting that the Lemaire-cutting method may only hold for more intensively managed systems. Accordingly, the Lemaire-cutting method might overestimate critical $\mathrm{N}$ uptake in lower cutting systems. In any case, these differences may represent resource limitations not captured within the $\mathrm{N}$ dilution curve.

Both the Lemaire-cutting and calibrated Lemaire-cutting methods showed the expected approach to steady state of critical $\mathrm{N}$ uptake as biomass yield increased. Observed data did not show this trend, perhaps due to cutting of younger grass material or fewer data points with larger biomass yields (Fig. 4). Critical N uptake calculations with 4-cut system data might better show this typical leveling of $\mathrm{N}$ uptake because of four cuts, which include one early in the season with low biomass and high $\mathrm{N}$ concentration and one late with high biomass and low $\mathrm{N}$ concentration. The measurement of older and partly senesced plant material would provide data points for the later cut in the growing season. However, as previously mentioned, our data are limited for 2-cut system data, so only 3- and 4-cut systems were considered.

\subsection{Potential application of the $\mathrm{N}$ dilution curve in experimental methods and simulation models}

In general, characterizing the $\mathrm{N}$ budget of managed grasslands is quite difficult and large uncertainties exist in current experimental and modeling methods (Ammann et al. 2009). Estimating the amount of $\mathrm{N}$ that enters and leaves the agroecosystem is important to reduce environmental impacts and also increase agricultural productivity through $\mathrm{N}$ use efficiency (Cassmann et al. 2002; Godinot et al. 2015). Recent work by Godinot et al. (2015) proposed a system N use efficiency, taking into account net inputs and outputs, such as atmospheric $\mathrm{N}$ deposition, feed and litter, and biological $\mathrm{N}$ fixation. In managed grasslands, specifically ones that are frequently cut, using the appropriate calculation method for potential $\mathrm{N}$ uptake by plants could be used as evaluation in a system $\mathrm{N}$ use efficiency calculation or for approximation of $\mathrm{N}$ loss due to frequent defoliation.

Large-scale models often only have a simplistic representation of $\mathrm{N}$ uptake related to agricultural management. Plant $\mathrm{N}$ uptake determines the dynamics of coupled $\mathrm{C}-\mathrm{N}$ models on longer time scales because this component interacts with microbial competition for N (Zaehle and Dalmonech 2011). A majority of coupled $\mathrm{C}-\mathrm{N}$ models calculate $\mathrm{N}$ uptake in relation to immobilization of $\mathrm{N}$ in litter or the root mass (Zaehle and Dalmonech 2011). While most models do not consider the human influence on plant $\mathrm{N}$ uptake, it is suggested that experiments with $\mathrm{N}$ fertilization effects on uptake be used to improve this model component (Zaehle and Dalmonech 2011). 
The large differences among the $\mathrm{N}$ uptake calculation methods provide some indication of the potential uncertainty in $\mathrm{N}$ uptake calculations from managed grasslands. Recently, Hidy et al. (2012) improved simulations of grasslands within Biome-BGC, a biogeochemical model that looks at $\mathrm{C}, \mathrm{N}$, and water within the terrestrial biosphere, and also included parameters to simulate cutting. Further research can look at the differences in $\mathrm{N}$ uptake if the $\mathrm{N}$ dilution curve is included in simulations as well as the variability of $\mathrm{N}$ uptake between the empirical relationships and process-based models' output. The latter can provide insight into how the $\mathrm{N}$ dilution curve and inclusion of management, such as cutting, may better inform $\mathrm{N}$ uptake and cycling within process-based models.

\section{Conclusion}

Management of grasslands plays a major role in determining plant $\mathrm{N}$ uptake. We found different $\mathrm{N}$ dilution curve parameters across a range of cutting systems. Different $\mathrm{N}$ uptake calculation methods based on these calibrated parameters demonstrated the variability of $\mathrm{N}$ uptake with respect to data availability and management. An overestimation of $\mathrm{N}$ uptake can occur without taking into account cutting regime information resulting in erroneous $\mathrm{N}$ balances. Under or overestimation of $\mathrm{N}$ uptake can have substantial implications for grassland management strategies and $\mathrm{N}$ cycling processes in simulation models. As a first step in analyzing the coupled nature of management activities and ecosystem processes, improved estimates of $\mathrm{N}$ uptake can be useful to managers and farmers in maintaining the sustainable use of their land, but also scientists in constraining and evaluating model processes and output related to the $\mathrm{N}$ cycle.

Acknowledgments This work was made possible by funding through the United States Department of State Fulbright program. The authors thank Sarah Anderson and Jake Gray for proofreading and comments. In addition, Frank Ewert and Jürgen Schellberg acknowledge the support of the German Research Foundation (DFG) through financing the Collaborative Research Center 1501 for research on rangeland management and modeling.

\section{References}

Agnusdei M, Assuero S, Lattanzi F, Marino M (2010) Critical N concentration can vary with growth conditions in forage grasses: implications for plant $\mathrm{N}$ status assessment and $\mathrm{N}$ deficiency diagnosis. Nutr Cycl Agroecosyst 88:215-230. doi:10.1007/s10705-010-9348-6

Ammann C, Spirig C, Leifeld J, Neftel A (2009) Assessment of the nitrogen and carbon budget of two managed temperate grassland fields. Agric Ecosyst Environ 133:150-162. doi:10.1016/j.agee. 2009.05.006

Bestelmeyer BT, Briske DD (2012) Grand challenges for resilience-based management of rangelands. Rangel Ecol Manag 65:654-663. doi: 10.2111/REM-D-12-00072.1
Bondeau A, Smith PC, Zaehle S et al (2007) Modelling the role of agriculture for the 20th century global terrestrial carbon balance. Glob Chang Biol 13:679-706. doi:10.1111/j.1365-2486.2006.01305.x

Burton GW, Jackson JE, Hart RH (1963) Effects of cutting frequency and nitrogen on yield, in vitro digestibility, and protein, fiber, and carotene content of coastal Bermudagrass1. J Agron 55:500. doi:10. 2134/agronj1963.00021962005500050027x

Cassman KG, Dobermann A, Walters DT (2002) Agroecosystems, nitrogen-use efficiency, and nitrogen management. Ambio 31:132-140

Dahl BE, Hyder DN (1977) Developmental morphology and management implications. In: Sosebee RE (ed) Rangeland plant physiology. Society for Range Management, Denver, Colorado, pp 257-290

Dunteman GH (1989) Principal components analysis. SAGE

Elsäßer M (1999) Auswirkungen reduzierter Stickstoffdüngung auf Erträge, Futterwert und Botanische Zusammensetzung von Dauergrünland sowie Nährstoffverhältnisse im Boden. Habilitationsschrift, Universität Hohenheim, Wissenschaftsverlag Dr. Fleck, Gießen

Fairey NA (1991) Effects of nitrogen fertilizer, cutting frequency, and companion legume on herbage production and quality of four grasses. Can J Plant Sci 71:717-725. doi:10.4141/cjps91-105

Farruggia A, Gastal F, Scholefield D (2004) Assessment of the nitrogen status of grassland. Grass Forage Sci 59:113-120. doi:10.1111/j. 1365-2494.2004.00411.x

Flénet F, Guérif M, Boiffin J et al (2006) The critical N dilution curve for linseed (Linum usitatissimum L.) is different from other $\mathrm{C} 3$ species. Eur J Agron 24:367-373. doi:10.1016/j.eja.2006.01.002

Galloway JN, Aber JD, Erisman JW et al (2003) The nitrogen cascade. Bioscience 53:341-356. doi:10.1641/0006-3568(2003) 053[0341:TNC]2.0.CO;2

Gastal F, Lemaire G (2002) N uptake and distribution in crops: an agronomical and ecophysiological perspective. J Exp Bot 53:789 799. doi:10.1093/jexbot/53.370.789

Gibon A (2005) Managing grassland for production, the environment and the landscape. Challenges at the farm and the landscape level. Livest Prod Sci 96:11-31. doi:10.1016/j.livprodsci.2005.05.009

Gislum R, Boelt B (2009) Validity of accessible critical nitrogen dilution curves in perennial ryegrass for seed production. Field Crop Res 111:152-156. doi:10.1016/j.fcr.2008.11.009

Godinot $\mathrm{O}$, Leterme P, Vertès F, et al (2015) Relative nitrogen efficiency, a new indicator to assess crop livestock farming systems. Agron Sustain Dev 35:857-868. doi:10.1007/s13593-015-0281-6

Greenwood DJ, Lemaire G, Gosse G et al (1990) Decline in percentage N of $\mathrm{C} 3$ and $\mathrm{C} 4$ crops with increasing plant mass. Ann Bot 66:425436

Gruber L, Steinwidder A, Stefanon B et al (1999) Influence of grassland management in Alpine regions and concentrate level on $\mathrm{N}$ excretion and milk yield of dairy cows. Livest Prod Sci 61:155-170. doi:10. 1016/S0301-6226(99)00065-2

Herrmann A, Kelm M, Kornher A, Taube F (2005) Performance of grassland under different cutting regimes as affected by sward composition, nitrogen input, soil conditions and weather - a simulation study. Eur J Agron 22:141-158. doi:10.1016/j.eja.2004.02.002

Herrmann A, Taube F (2004) The range of the critical nitrogen dilution curve for Maize (L.) can be extended until silage maturity. Agron J 96:1131. doi:10.2134/agronj2004.1131

Hidy D, Barcza Z, Haszpra L et al (2012) Development of the BiomeBGC model for simulation of managed herbaceous ecosystems. Ecol Model 226:99-119. doi:10.1016/j.ecolmodel.2011.11.008

Justes E, Mary B, Meynard J-M et al (1994) Determination of a critical nitrogen dilution curve for winter wheat crops. Ann Bot 74:397407. doi:10.1006/anbo.1994.1133

Kemp DR, Michalk DL (2007) Towards sustainable grassland and livestock management. J Agric Sci 145:543-564. doi:10.1017/ S0021859607007253 
Lemaire G, Gastal F (1997) N uptake and distribution in plant canopies. In: Lemaire $G$ (ed) Diagnosis of the nitrogen status in crops. Springer, Berlin, pp 3-43

Lemaire G, Jeuffroy M-H, Gastal F (2008) Diagnosis tool for plant and crop N status in vegetative stage: theory and practices for crop N management. Eur J Agron 28:614-624. doi:10.1016/j.eja.2008.01. 005

Leps J, Smilauer P (2003) Multivariate analysis of ecological data using CANOCO. Cambridge University Press, Cambridge

Madakadze IC, Stewart KA, Peterson PR, et al (1999) Cutting Frequency and Nitrogen Fertilization Effects on Yield and Nitrogen Concentration of Switchgrass in a Short Season Area. Crop Science 39:552. doi:10.2135/cropsci1999. 0011183X003900020041x

Marino MA, Mazzanti A, Assuero SG et al (2004) Nitrogen dilution curves and nitrogen use efficiency during winter-spring growth of annual ryegrass. Agric J 96:601. doi:10.2134/agronj2004.0601

Matson PA, Parton WJ, Power AG, Swift MJ (1997) Agricultural intensification and ecosystem properties. Science 277:504-509. doi:10. 1126/science.277.5325.504

Nevens F, Rehuel D (2003) Effects of cutting or grazing grass swards on herbage yield, nitrogen uptake and residual soil nitrate at different levels of N fertilization. Grass Forage Sci 58:431-449. doi:10.1111/ j.1365-2494.2003.00396.x

Parton WJ, Scurlock JMO, Ojima DS et al (1995) Impact of climate change on grassland production and soil carbon worldwide. Glob Chang Biol 1:13-22. doi:10.1111/j.1365-2486.1995.tb00002.x

Pavlů V, Schellberg J, Hejcman M (2011) Cutting frequency vs. N application: effect of a 20-year management in Lolio-Cynosuretum grassland. Grass Forage Sci 66:501-515. doi:10.1111/j.1365-2494.2011. 00807.x

Whitehead DC (1995) Grassland nitrogen. CAB International

Wilman D, Wright PT (1986) The effect of interval between harvests and nitrogen application on the concentration of nitrate-nitrogen in the total herbage, green leaf and "stem" of grasses. J Agric Sci 106:467475. doi:10.1017/S0021859600063346

Zaehle S, Dalmonech D (2011) Carbon-nitrogen interactions on land at global scales: current understanding in modelling climate biosphere feedbacks. Curr Opin Environ Sustain 3:311-320. doi:10.1016/j. cosust.2011.08.008

Zhang Y, Bunting LD, Kappel LC, Hafley JL (1995) Influence of nitrogen fertilization and defoliation frequency on nitrogen constituents and feeding value of annual ryegrass. J Animal Sci 73:2474-2482 